\title{
UHF RFID Read Range Control Based on Visual Basic.NET for Automation Tool's Crib
}

\author{
Aldo Rahmad Ageng ${ }^{1}$, Ari Santoso ${ }^{2}$, Imam Arifin ${ }^{1}$, Ayyasy Azzurqi ${ }^{3}$, and Moh. Abdul Hady ${ }^{2}$
}

\begin{abstract}
Asset maintenance is a preventive action from tool's damage. Place for production tool's usually called by tool's crib, is a facility for field engineer on the production line. Generally, tool's maintaining system that operate in industry checked and maintain in every month. Nevertheless, administration check and maintenance are unbalanced that delayed transactional and identification process. Automating tool's crib applied to change transaction and administration activity on the system become automatic using RFID (Radio Frequency Identification) and database on Automation Tool's Crib project. Used RFID on this project have a read range that far too wide on the identification process. So, controlling read range of a RFID on Automation tool's Crib to reduce error on transaction and identification process. Controlling RFID based on Visual Basic.NET are able to reduce error of scanning process on Automation Tool's Crib from $7.5 \%$ to $1.2 \%$.
\end{abstract}

Keywords-Automation, RFID, Tool's Crib.

\section{INTRODUCTION}

Identify and solving problem on industrial environment especially in factory automation as a student just can be achieved by doing internship. On the professional world of engineering, to adapt with the industrial environment should make student to be widely think about practical matters other than theory on books to solve problem and phenomenon on the industry.

Knowledge about machine making process give a challenge to us as a internship to interact with the industry by solving problem with making a practical machine that can be used to help line production field engineer. Tool's crib needed a separation method to differentiate tools that on the cabinet, outside of the cabinet, and card identity of user. To increase effectivity of the tool's crib by automate service and administration. Separating RFID tag data type by controlling read range to increase read accuracy of RFID to tool's tag. On this final project will be created a machine that support the operational of the automation tool's crib. The machine use filling cabinet that will be equipped with solenoid door

\footnotetext{
${ }^{1}$ Aldo Rahmad Ageng and Imam Arifin are with Department of Automation Electrical Engineering, Institut Teknologi Sepuluh Nopember, Surabaya, 60111, Indonesia. E-mail: arifin-i@ee.its.ac.id.

${ }^{2}$ Ari Santoso and Moh. Abdul Hady are with Department of Electrical Engineering, Institut Teknologi Sepuluh Nopember, Surabaya, 60111, Indonesia.

${ }^{3}$ Ayyasy Az Zurqi is with Winteq Division of Astra Otoparts, Cibinong, Indonesia.
}

lock to lock cabinet doors as a security action. Mid-range RFID will be used too as a tool's identification that will be identify tool's on the inside and the outside the cabinet. So that the tools that borrowed and placed on the cabinet can be detected using RFID read range control based on database that record transaction and main information from the tools and the user automatically.

\section{AUTOMATION TOOL'S CRIB SYSTEM}

\section{A. Tools Management}

Tools management system is an effort to integrate some function of the tools including tools monitoring, transportation, inventory management, and purchasing. To determine range the function from the method is to know information flow that on the manufacture system that previously integrate In the industry. The activity flow include: product design,, process planning, scheduling and resource planning, and production control.

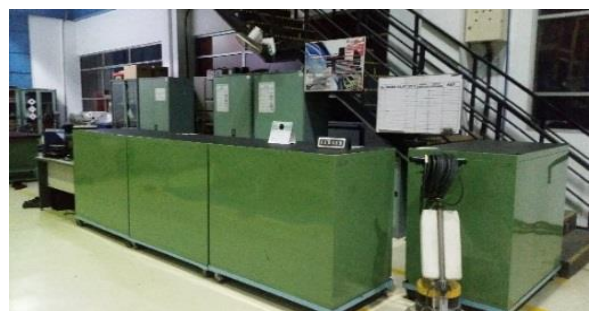

Figure 1. Tool's crib on the PT. Astra Otoparts WINTEQ Division.

Information that connect to the management consist into 2 area. First is a directional command that pictured as with an arrow from management block to the three main function. Every function have to report to management as a feedback that will be used by management to measure performance of the unit objectively. On the diagram, production control divided into 3 block, there is : factory control, workstation control, and machine control. Divided sub part showing that every department from the production facility divided into a group that communicate based on control architecture of the production facility. On the inside lateral integration of the production control, scheduling, product design and process planning, is a support system of the manufacturing system that using database to communicate each other. For example, the product design department can read design reference on the database. process planning can access the data and geometric features of the CAD database and make process planning in the process database. Resource planning and 
scheduling can access process planning to produce results from the production system.

\section{B. Tool's Crib System}

The crib tool system is part of equipment management which aims to increase the productivity of the production part and as a monitoring of the condition of the equipment during use. There is some procedure that applied to the system is :

1. Inspection, recondition and disposal.

Tool's crib monitors and evaluates equipment used in the production section, for example standard equipment, drills, and end mills. Equipment that is monitored by the system, can be given immediate action if damage occurs or requires replacement. The act of repairing or returning to normal conditions on equipment that is not used up is one of the tasks of the system tool's crib, namely reconditioning

2. Presetting

Adjustment of equipment by use in the production line becomes the task of the unit tool's crib to prepare. Use of equipment that requires a particular configuration to be used needs to be re-calibrated every day.

3. Requisition unit tools

The next stage of recondition and disposal is the replacement of the equipment with a new one. adjustment of needs is a consideration for adding new equipment.

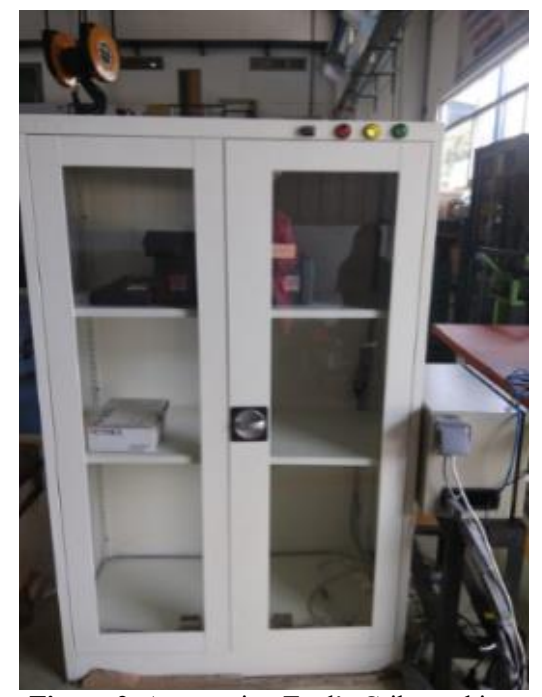

Figure 2. Automation Tool's Crib machine.

\section{Tool inventory}

The management of the equipment in the storage tool's crib in large quantities, requires that the system provide customized equipment information future manufacturing activity, Equipment grouping based on uniform production activity usage, enables users to reduce the need for additional equipment for production, age of use of equipment to be monitored and maintained so equipment can be used for long periods of time, and duplicate inventory the equipment in the tool's crib storage, has been adjusted to the number of machines and operations that will take place in one day, so that the equipment used for production is available for all available machines with simultaneous operating times without interfering with each other.

\section{RFID ( Radio Frequency Identification)}

RFID is a system that is remotely and wirelessly used to identify other equipment called transponders or commonly called tags using interrogators or readers. Tags have unique identities that are commonly used to identify marked objects. RFID technology is divided into 2 main categories, namely active and passive RFID. RFID technology commonly used today is a passive category, because transponders do not have their own energy source. However, the transponder is powered by the electromagnetic field released by the interrogator which is converted to electric power. On active transponder technology, the working distance can exceed the passive category, because it has its own power source.

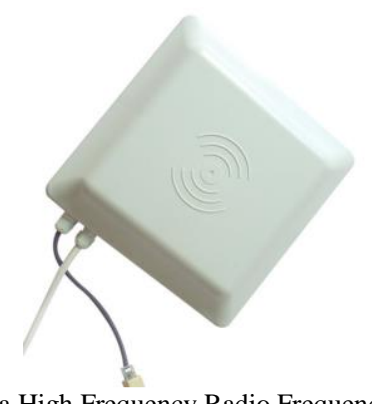

Figure 3. Ultra High Frequency Radio Frequency Identification Interrogator.

\section{Interrogator}

Interrogators or commonly called RFID transmitters are part of an RFID system that is used to send signals to a transponder or receiver so that data can be received. There are two main tasks of this tool, the first in the downlink phase to provide power to passive tags and signal modulation so that passive tags receive commands and data from the device, and in the uplink phase, the interrogator must provide an unmodulated signal so that the tag is able to return data to sender. Interrogators are important tools in RFID systems, therefore they must be used in many radio frequency channels accurately, and can be moved to other channels quickly to adjust to usage. A good transmitter in an RFID system is one that has a good reading distance, so that to meet these requirements a large amount of power is needed to be received by the tag.

\section{Transponder}

The communication system on RFID, to complete the system needed a device that provides signal feedback to the interrogator when sending information signals, the transponder can receive signals from the interrogator if it has the same frequency, protocol and orientation in both communication devices. Limitations of passive tags are in the feedback signal modulation which has a variable frequency, so that in passive tags, problems with demodulation and decoding rarely occur, compared to using radio communication with technology based on phase 
signals and amplitude with error-correcting codes. Beside, passive tags have problems in interference signals that block the signal from the transmitter to be able to provide feedback, or interference on the bounce signal of the tag.

\section{READ RANGE CONTROL PROGRAM DESIGN}

Transmission power from RFID with UHF frequency can reach up to 4 meters. a cabinet that has 1.5 meters requires setting the reading distance to make the tag read more effective and the outside of the cabinet unreadable. Beyond the parameters of the power settings, the RFID tag also adjusts the orientation and position with the reader. Proper power settings will determine the validity of the data read when scanning equipment. Arrangements are made when scanning the user card at the start of the procedure as well as when scanning equipment for the first or second. The user's scanning process uses a transmit power of $20 \mathrm{~dB}$ which changes in decrement to ensure that the user in the closest range position to use the service and in the scanning power process will change to $10 \mathrm{~dB}$ and will increase the read capacity per millisecond

\section{TRIAL AND ANALYSIS}

\section{A. RFID Communication Test}

Communication Test aims to find out the RFID's ability of speed to transmit serial data by reading the EPCC1-G2 type RFID tag. Selection of data communication methods on RFID aims to compare the existing configuration of serial communication which is one of the media that can be used on RFID. Configuring the RFID configuration leads to the preset of the serial cable with the need for cable adjustments on the machine.

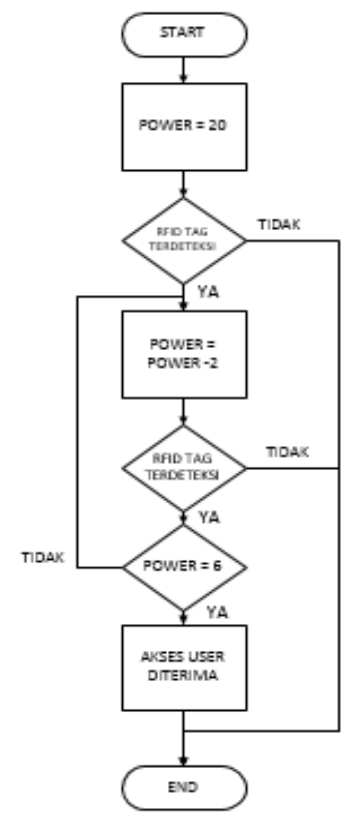

Figure 4. Read Range Control Program Flowchart.
TABLE 1. RFID COMMUNICATION TEST RESULT

\begin{tabular}{ccccc}
\hline \hline $\begin{array}{c}\text { Baud } \\
\text { Rate }\end{array}$ & $\begin{array}{c}\text { Kekuatan } \\
(\mathbf{d B})\end{array}$ & $\begin{array}{c}\text { Frekuensi } \\
(\mathbf{H z})\end{array}$ & $\begin{array}{c}\text { Jumlah } \\
\text { alat } \\
\text { tersedia }\end{array}$ & $\begin{array}{c}\text { Alat yang } \\
\text { terbaca }\end{array}$ \\
\hline \multirow{6}{*}{5} & & & 0 \\
& 10 & $902.6-927.4$ & & 7 \\
& 20 & & 7 & 7 \\
& 30 & & & 0 \\
9600 & 5 & & 7 & 7 \\
& 10 & $920-924$ & & 7 \\
& 20 & & & 0 \\
& 30 & & & 0 \\
& 5 & & & 0 \\
\hline \hline
\end{tabular}

TABLE 2.

RFID READ RANGE TEST

\begin{tabular}{|c|c|c|}
\hline Rotation Degree (deg) & Linear Intensity $(\mathrm{dB})$ & $\begin{array}{c}\text { Radial } \\
\text { Intensity }(\mathbf{d B})\end{array}$ \\
\hline 0 & 30 & 1000 \\
\hline 10 & 30 & 1000 \\
\hline 20 & 30 & 1000 \\
\hline 30 & 30 & 1000 \\
\hline 40 & 30 & 1000 \\
\hline 50 & 30 & 1000 \\
\hline 60 & 30 & 1000 \\
\hline 70 & 28 & 630.957 \\
\hline 80 & 27 & 501.187 \\
\hline 90 & 24 & 251.189 \\
\hline 100 & 12 & 15.8489 \\
\hline 110 & 6 & 3.98107 \\
\hline 120 & 6 & 3.98107 \\
\hline 130 & 6 & 3.98107 \\
\hline 140 & 8 & 6.30957 \\
\hline 150 & 8 & 6.30957 \\
\hline 160 & 7 & 5.01187 \\
\hline 170 & 6 & 3.98107 \\
\hline 180 & 5 & 3.16228 \\
\hline 190 & 6 & 3.98107 \\
\hline 200 & 7 & 5.01187 \\
\hline 210 & 8 & 6.30957 \\
\hline 220 & 8 & 6.30957 \\
\hline 230 & 8 & 6.30957 \\
\hline 240 & 9 & 7.94328 \\
\hline 250 & 9 & 7.94328 \\
\hline 260 & 15 & 31.6228 \\
\hline 270 & 17 & 50.1187 \\
\hline 280 & 30 & 1000 \\
\hline 290 & 30 & 1000 \\
\hline 300 & 30 & 1000 \\
\hline 310 & 30 & 1000 \\
\hline 320 & 30 & 1000 \\
\hline 330 & 30 & 1000 \\
\hline 340 & 30 & 1000 \\
\hline 350 & 30 & 1000 \\
\hline
\end{tabular}

\section{B. RFID Read Range Radiation Test}

Radiation testing on RFID done in a spacious room with no obstruction around the room, by measuring the antenna radiation pattern based on RFID transmit power at every 10 ${ }^{\circ}$ around the tool. The measurement aims to determine the configuration of the transmit power and the placement of the 
International Conference on Engineering, Advance Science and Industrial Application (ICETESIA) 2018 September 6-7 2018, Institut Teknologi Sepuluh Nopember, Surabaya, Indonesia

device so as to be appropriate for use. The following is an illustration of the test method in Figure 4. and the test result data in Table 2.

From the data above shows that, the measurement of each rotation data is linear data so that to calculate radial intensity using Equation 1.

$$
I_{R}=10^{\frac{I_{\text {Iin }}}{10}}
$$

Data that has been taken at each angle to measure radiation patterns from RFID, is described using the graph in Figure 5. to find out the radiation patterns of RFID.

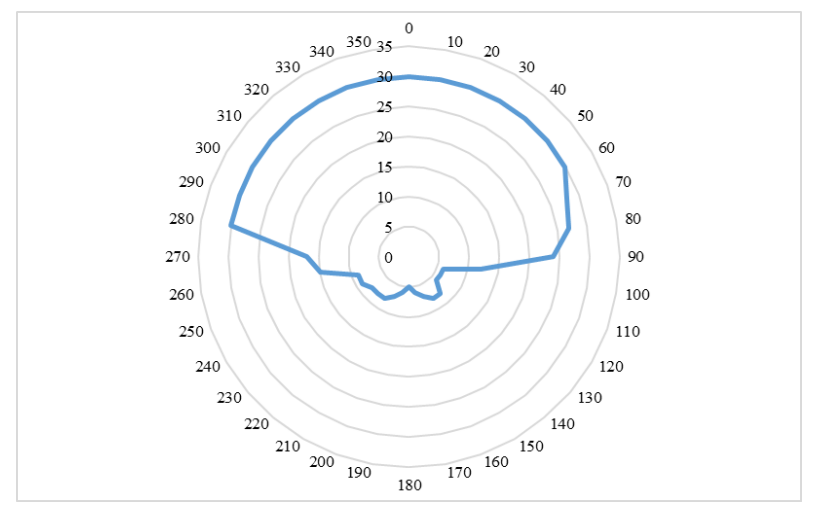

Figure 5. RFID CT-1809 Horizontal Radiation Pattern

\section{CONCLUSION}

Based on the results of the tests and analyzes that have been carried out, it can be concluded that the use of RFID as a user and equipment identification system in the Automation tool's crib increases the effectiveness and saves processing time. The process of sorting data using a Microsoft Access database as a database successfully separates user data and equipment that is detected at any time by the reader to be separated according to the procedure stage. Radiation pattern measurement results from UHF RFID helps simplify the reading distance from the previous tool with an error percentage of $7.5 \%$ to $1.6 \%$ reducing the occurrence of reading errors on the device. The next research from the system is suggested to use tags that are specific to work equipment and UHF type RFID that are able to adapt to environmental conditions in an industry that is full of interference so that the Automation Tool's Crib system can be used completely to replace conventional Tool's Crib

\section{REFERENCES}

[13] A. Ramos, A. Lazaro, D. Girbau, and R. Villarino, RFID and Wireless Sensors Using Ultra-Wideband Technology. 2016.

[14] M. Tap, J. R. Hewit, and S. Meeran, "An active tool-tracking system for increased productivity," Int. J. Prod. Res., vol. 38, no. 16, pp. 3889-3898, 2000.

[15] J. S. Sun and C. H. Wu, "A broadband circularly polarized antenna of square-ring patch for UHF RFID reader applications," AEU - Int. J. Electron. Commun., vol. 85, no. December 2017, pp. 84-90, 2018.

[16] M. Omer and G. Y. Tian, "Indoor distance estimation for passive UHF RFID tag based on RSSI and RCS," Measurement, vol. 127, no. May, pp. 425-430, 2018.

[17] S. C. Gii and J. C. Caeiro, Advances in Electrical Engineering and Electrical Machines, vol. 134, no. 6. 2011. 